\title{
A Study on the Uncertainty of Estimation in Vibration Test for the Machine Parts
}

\author{
Jae-Deok Hwang*, Chae-Sil Kim* ${ }^{\#}$ Sung-Jin Cho* \\ (* VIDEC Changwon National University, \# Changwon National University) \\ 가공 기계부품 고유진동수 해석과 측정에 관한 연구 \\ 황재덕*, 김재실 ${ }^{\#}$, 조성진 ${ }^{* *}$
}

(Received 3 February 2014; received in revised form 13 February 2014; accepted 20 February 2014)

\begin{abstract}
Resonance refers to the magnification of a structural response which occurs when a linear lightly damped system is driven with a sinusoidal input at its natural frequency. An exploratory vibration test (a natural frequency measurement test) is very important for the vibration testing of machine parts, as the value measured in an actual laboratory affects test results. For this reason, it is necessary to estimate the measurement uncertainty to verify the reliability of this type of test. In this study, measurement uncertainty is estimated based on three uncertainty factors. The uncertain factors are the measured points in the machine parts, the resolution of the vibration equipment, and uncertainty of the calibration certificate.
\end{abstract}

Key Words : Vibration(진동), Natural Frequency(고유진동수), Uncertainty(불확도)

\section{Introduction}

Generally, natural frequency measurement of parts served as a very valuable means of evaluation of the characteristic and durability of parts in the design and development processes in the electric, electronic, machine and automobile industries. Recently, evaluations of product along with machine part

\footnotetext{
* Vibration Induced Durability Evaluation Center, Changwon National University

\# C. A. : Department of Mechanical Engineering, Chagwon National University

E-mail : kimcs@changwon.ac.kr
}

evaluation tests are increasingly being used. Moreover, these tests tend to require detailed and minute analyses and measurements when nuclear power earthquake-proof designs are devised and related verification steps are conducted.

This paper evaluates the reliability of measurements by comparing the first-mode frequencies from a mode analysis with the measured natural frequencies of manufactured machine parts.

\section{Mode Analysis}

A 3D model consisting of steel machine parts 
and an aluminum jig were devised using CATIA. Next, a mode analysis was conducted using the 3D model in ANSYS Workbench. The material of the jig is aluminum alloy and the material of the machine parts is structural steel. The size of the finite elements is $3 \mathrm{~mm}$. Fig. 1 shows the finite element model and Fig. 2 shows the results of the mode analysis. Table 1 lists the mode analysis results for the machine parts.

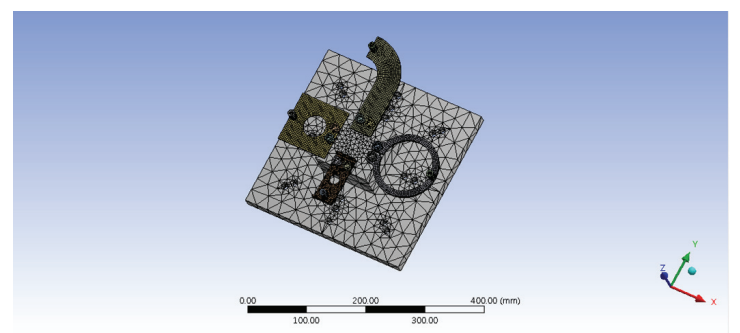

Fig. 1 Finite element model

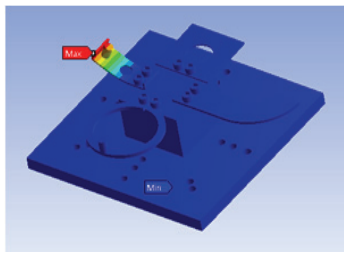

(a) Washer1

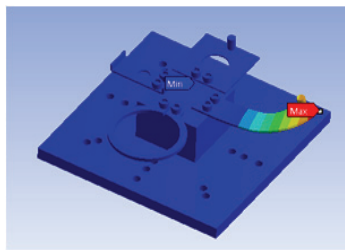

(c) Shroud

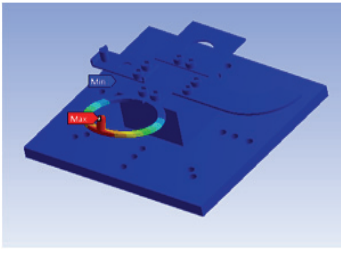

(b) Ring

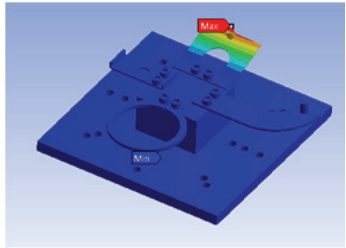

(d) Washer2
Fig.2 First-mode of the machine parts

Table 1 Natural Frequencies

\begin{tabular}{cc}
\hline & Natural frequency \\
\hline Washer1 & $310.65 \mathrm{~Hz}$ \\
\hline Ring & $232.78 \mathrm{~Hz}$ \\
\hline Shroud & $144.17 \mathrm{~Hz}$ \\
\hline Washer2 & $241.55 \mathrm{~Hz}$ \\
\hline
\end{tabular}

\section{Outline of Measurement Uncertainty}

In order to compare the results of the mode analysis with the measurement results, it is important to ensure the reliability of measurements. In order to ensure the reliability and the accuracy of the measurement, the uncertainty should be estimated.

The uncertainty is a parameter that signifies the distribution of the measurement and is an important main cause of error. Regarding the assumption of the measurement uncertainty, a numerical equation is devised and the factors that are affected by the measurement are listed. Those factors are then classified as A type standard uncertainty or B type standard uncertainty. After the combined standard uncertainty is determined as the sum of both of types, the expanded uncertainty is calculated by the multiplication of the coverage factor $\mathrm{k}$ and the combined standard uncertainty. The uncertainty of the measurements is then marked with the measured value and the expanded uncertainty. This assumption procedure related to the uncertainty comes from the "Guide to the expression of Uncertainty in Measurement" published by ISO in 1993. Fig. 3 demonstrates this assumption procedure.

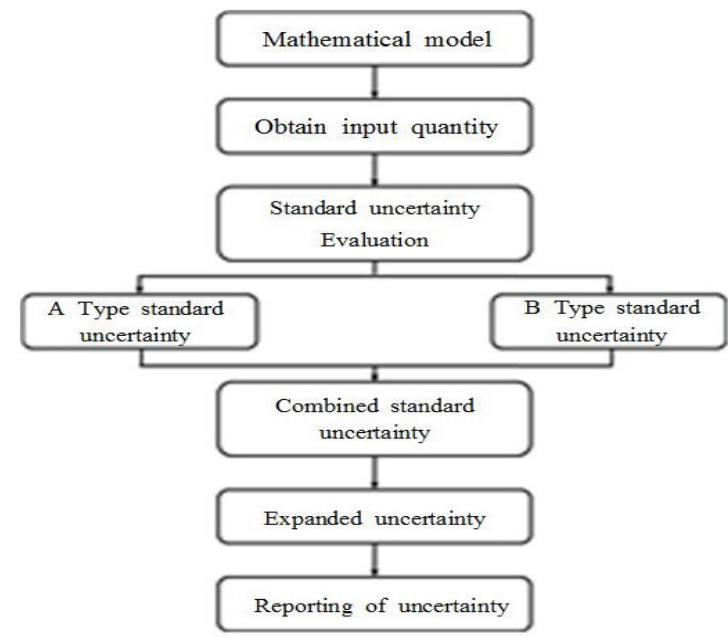

Fig. 3 Uncertainty estimation procedure 


\section{Assumption of Measurement Uncertainty}

This evaluation procedure stems from the "Guide to the Expression of Uncertainty in Measurement" as published by ISO in 1993. Fig. 3 shows the procedure for estimating uncertainty. Equation 1 is the natural frequency model equation that is idealized (by the author) for the machine part of a 1-DOF spring-mass system with stiffness $k$. If the information is not known for the machine parts, the natural frequency can be measured. Therefore, the natural frequency is assumed as an independent variable.

$$
w_{n}=\sqrt{\frac{k}{m}}
$$

( $w_{n}$ : natural frequency, $k$ : stiffness of spring, $m$ : mass)

A Type A evaluation of uncertainty refers to the uncertainty from repeated measurement. This Type A evaluation of uncertainty is statistically denoted as a series of observed value. The standard uncertainty is calculated from the average, the dispersion and the standard deviation of $\mathrm{n}$ measurement.

$$
u_{A}=\frac{s}{\sqrt{n}}
$$

Type A evaluation of uncertainty is expressed in Equation 2. Here, $\mathrm{n}$ is the number of the repeated measurement and $s$ is the standard deviation of the average of the measured values.

Type B evaluation of uncertainty is ascertained by experience or from other information instead of a statistical analysis. It is the uncertainty caused by the resolving power of the equipment used during in the measurements and by the calibration report of the accelerometer used during in the measurement. The uncertainty by the resolving power is calculated the dispersion of uniform distribution, as expressed in Equation 3.

$$
u_{B 1}=\frac{D / 2}{\sqrt{3}}
$$

Here, $D$ is the value of the resolving power of the equipment used in the experiment. Equation 4 expresses the uncertainty caused by the calibration report of an accelerometer. Here, $u$ is the relative standard uncertainty of the calibration report, and $k$ is the coverage factor.

$$
u_{B 2}=\frac{u}{k}
$$

Because the combined standard uncertainty can be independently determined without the correlation between the type A evaluation of uncertainty and the type B evaluation of uncertainty, the combined standard uncertainty can be calculated using the RSSM (root sum square method).

$$
u_{c}=\sqrt{u_{A}^{2}+u_{B 1}^{2}+u_{B 2}^{2}}
$$

Equation 6 expresses the expanded uncertainty, which is the multiplication the combined standard uncertainty $u_{c}$ and the coverage factor.

$$
U=k \times u_{c}
$$

It is assumed that the value of the expanded uncertainty is a normal distribution when the number of measurement exceeds 10. The expanded uncertainty can be found by defining the coverage factor $k=2$ with a 95-percent confidence level without calculating the effective degrees of freedom. However, when the number of measurements is less than 10, the coverage factor should be calculated with the assumption a t-distribution while calculating 
the effective degrees of freedom depending on the confidence level. Equation 7 expresses the equation used to determine the effective degrees of freedom. The sensitivity coefficient $c_{i}$ is to be 1 in this study because the functional relationship between the uncertainty factor and the natural frequency is difficult to define and express. The degrees of freedom of the type A evaluation of uncertainty, $v_{A}$, is the number of measurement minus one and the degrees of freedom of the type $B$ evaluation of uncertainty, $v_{B 1}$ and $v_{B 2}$, is nearly infinite.

$$
\begin{aligned}
v_{e f f} & =\frac{u_{c}^{4}(y)}{\sum_{i=1}^{n} \frac{u_{i}^{4}(y)}{v_{i}}}=\frac{u_{c}^{4}(y)}{\sum_{i=1}^{n} \frac{\left[c_{i} \times u\left(x_{i}\right)\right]^{4}}{v_{i}}} \\
= & \frac{u_{c}^{4}(y)}{\frac{u_{A}^{4}(y)}{v_{A}}+\frac{u_{B 1}^{4}(y)}{v_{B 1}}+\frac{u_{B 2}^{4}(y)}{v_{B 2}}}
\end{aligned}
$$

\section{Measurement Test}

Fig. 4 shows the 2D drawings of the machine parts used for measurements. These machine parts were manufactured with general tolerance levels. The measuring equipment used in the test is the J260 de vice by IMV, a general electronics vibration test machine. The accelerometer, model 4383 by $\mathrm{B} \& \mathrm{~K}$, is a charge type of machine. Its frequency range is $1 \sim$ $10 \mathrm{kHz}$.

According to KS R 1034 : 2006, the accelerometer is attached at the same direction, with sine vibration generated by a shaker. The natural frequency of the machine parts is repeatedly measured three times each in the control condition at a frequecny range of $5 \sim 400 \mathrm{~Hz}$, an acceleration of $0.5 \mathrm{~g}$ and a period of 2.0 octave $/ \mathrm{min}$.

Fig. 5 plots the acceleration for the frequency, indicating the input condition.

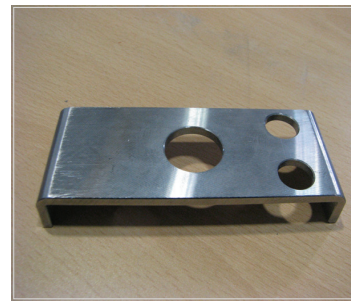

(a) Washer1

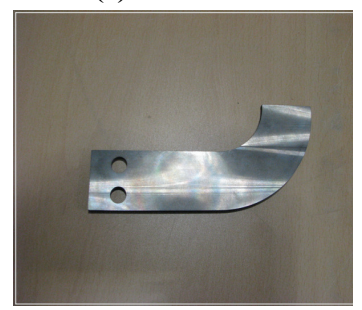

(c) Shroud

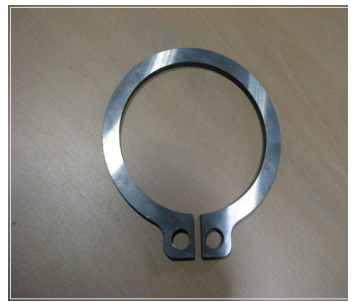

(b) Ring

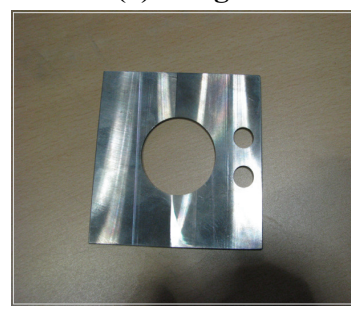

(d) Washer2

\section{Fig. 4 Machine Parts}

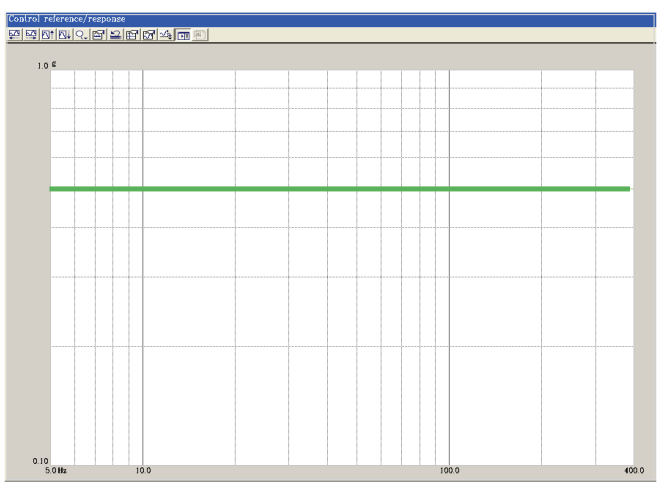

Fig. 5 Sine sweep test profile

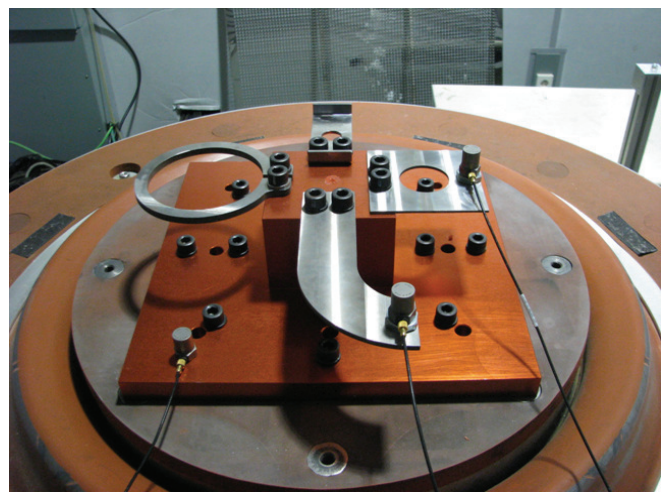

Fig. 6 Parts setting on vibration shaker 
Fig. 6 shows the machine parts installed onto the shaker, also showing the accelerometers attached onto the machine parts.

\section{Results and Discussion}

Table 2 lists the results of the measurement and Table 3 lists type A evaluation of uncertainty from the iterative measurements. Fig. 7 shows a graphs in which the $\mathrm{X}$ axis expresses the frequency and the $\mathrm{Y}$ axis expresses the acceleration.

Because the resolving power of the equipment used in the test used different value depending on the frequency range, the resolving power applied for the shroud is $1 \mathrm{~Hz}$ while that for the other machine parts is $2 \mathrm{~Hz}$. Table 4 lists the frequency resolution of equipments used in the test. According to Equation 3, the type $\mathrm{B}$ evaluation of uncertainty, $v_{B 1}$, as calculated by Equation 3, is listed in Table 6. When the coverage factor $k$ equals 2 at the 95-percent confidence level, the relative expanded uncertainties of the accelerometer in the test list are shown in Table 5. The relative expanded uncertainty

Table 2 Natural Frequency of Measured Data

\begin{tabular}{ccccc}
\hline & run 1 & run 2 & run 3 & ave. \\
\hline Washer1 & 312 & 314 & & 313.0 \\
\hline Ring & 220 & 222 & 226 & 222.7 \\
\hline Shroud & 142 & 145 & 137 & 141.3 \\
\hline Washer2 & 248 & 248 & 242 & 246.0 \\
\hline
\end{tabular}

Table 3 A Type Standard Uncertainty

\begin{tabular}{ccccc}
\hline & Washer1 & Ring & Shroud & Washer2 \\
\hline Average & 313.0 & 222.7 & 141.3 & 246.0 \\
\hline $\begin{array}{c}\text { Standard } \\
\text { deviation }\end{array}$ & 1.414 & 3.055 & 4.042 & 3.464 \\
\hline $\begin{array}{c}\text { Standard } \\
\text { uncertainty }\end{array}$ & 1.000 & 1.764 & 2.333 & 2.000 \\
\hline
\end{tabular}

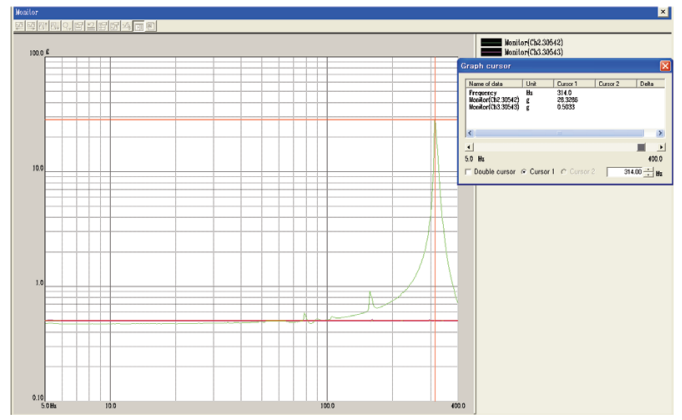

(a) Washer1

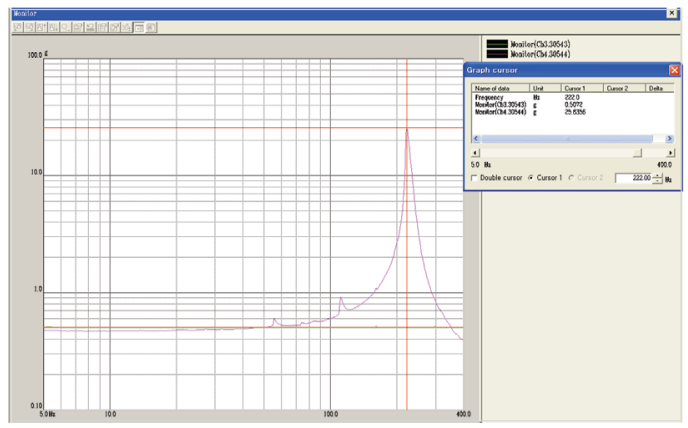

(b) Ring

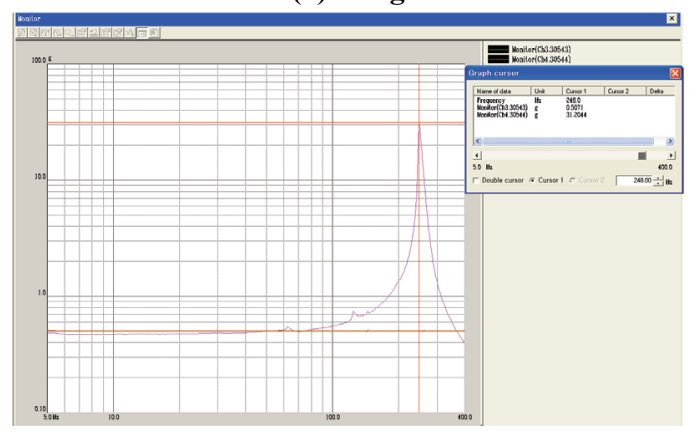

(c) shroud

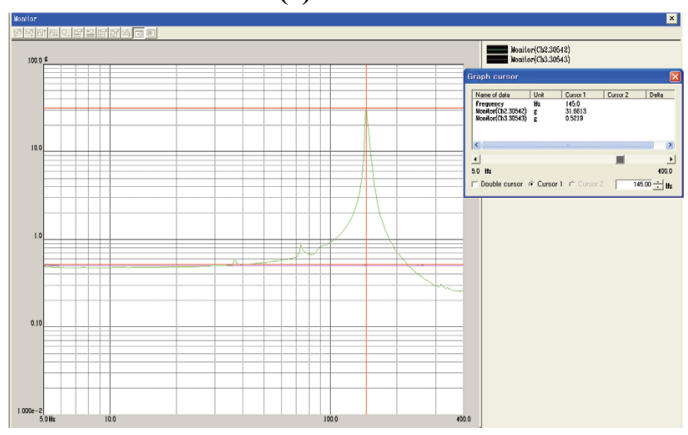

(d) Washer2

Fig. 7 Natural frequency of parts 
Table 4 Frequency Resolution

\begin{tabular}{ccc}
\hline \multicolumn{2}{c}{ Frequency range } & $\begin{array}{c}\text { Resolution } \\
(\mathrm{Hz})\end{array}$ \\
\hline \hline Lower.(Hz) & Upper $(\mathrm{Hz})$ & 0.1 \\
\hline 5 & 50 & 0.5 \\
\hline 50 & 100 & 1 \\
\hline 100 & 200 & 2 \\
\hline
\end{tabular}

Table 5 Expanded Uncertainty of Calibration Results

\begin{tabular}{cc}
\hline Frequency $(\mathrm{Hz})$ & Expanded uncertainty (\%) \\
\hline \hline 20 & 1.3 \\
\hline 40 & 1.2 \\
\hline 100 & 1.2 \\
\hline 160 & 1.2 \\
\hline 315 & 1.3
\end{tabular}

Table 6 B Type Standard Uncertainty

\begin{tabular}{ccccc}
\hline & Washer1 & Ring & Shroud & Washer2 \\
\hline \hline$u_{B 1}$ & $0.578 \mathrm{~Hz}$ & $0.578 \mathrm{~Hz}$ & $0.289 \mathrm{~Hz}$ & $0.578 \mathrm{~Hz}$ \\
\hline$u_{B 2}$ & $2.035 \mathrm{~Hz}$ & $1.448 \mathrm{~Hz}$ & $0.848 \mathrm{~Hz}$ & $1.599 \mathrm{~Hz}$ \\
\hline
\end{tabular}

is applied $1.2 \%$ at the shroud and $1.3 \%$ at the other machine parts. The type $B$ evaluation of uncertainty, $u_{B 2}$, is calculated, as shown in Table 6 .

By using Equation 5, the combined standard uncertainty is determined, as shown in Table 7. In order to find the coverage factor $k$, the effective degrees of freedom are determined by calculating the sum of the components of uncertainty and the degrees of freedom pertaining to the combined standard uncertainty. Table 8 lists the effective degrees of freedom calculated by Equation 7. After
Table 7 Combined Standard Uncertainty

\begin{tabular}{ccccc}
\hline & Washer1 & Ring & Shroud & Washer2 \\
\hline \hline$u_{c}$ & $2.340 \mathrm{~Hz}$ & $2.355 \mathrm{~Hz}$ & $2.500 \mathrm{~Hz}$ & $2.625 \mathrm{~Hz}$ \\
\hline
\end{tabular}

Table 8 Degree Of Freedom

\begin{tabular}{lcccc}
\hline & Washer1 & Ring & Shroud & Washer2 \\
\hline \hline$v_{\text {eff }}$ & 29.982 & 6.354 & 2.633 & 5.935 \\
\hline
\end{tabular}

Table 9 Expander Uncertainty

\begin{tabular}{ccccc}
\hline & Washer1 & Ring & Shroud & Washer2 \\
\hline \hline$U$ & $4.774 \mathrm{~Hz}$ & $5.558 \mathrm{~Hz}$ & $7.950 \mathrm{~Hz}$ & $6.432 \mathrm{~Hz}$ \\
\hline
\end{tabular}

Table 10 Comparison of Natural Frequency

\begin{tabular}{ccc}
\hline & 1st mode data & Measured data \\
\hline \hline Washer1 & $310.65 \mathrm{~Hz}$ & $(313.0 \pm 4.774) \mathrm{Hz}$ \\
\hline Ring & $232.78 \mathrm{~Hz}$ & $(222.7 \pm 5.558) \mathrm{Hz}$ \\
\hline Shroud & $144.17 \mathrm{~Hz}$ & $(141.3 \pm 7.950) \mathrm{Hz}$ \\
\hline Washer2 & $241.55 \mathrm{~Hz}$ & $(246.0 \pm 6.432) \mathrm{Hz}$ \\
\hline
\end{tabular}

the coverage factor $k$ is calculated from a t-distribution table, the expanded uncertainty of each machine parts is calculated, as shown in Table 9.

The results of the natural frequency measurements of each machine part were determined. In these mea surements of the natural frequencies, the value for the washer of rolling bearing is $313.0 \pm 4.774 \mathrm{~Hz}$ at the 95-percent confidence level with $k=2.45$; that for the ring is $222.7 \pm 5.558 \mathrm{~Hz}$ at the 95-percent confidence level with $k=2.36$; that for the shroud is $141.3 \pm 7.950 \mathrm{~Hz}$ at the 95-percent confidence level with $k=3.18$; and that for the rectangular large washer is $246.0 \pm 6.432 \mathrm{~Hz}$ at the 95-percent confidence level at $k=2.45$. From a comparison of the analytical results and the measured results, the 
natural frequencies of all other machine parts except for the ring are within limit of the uncertainty of measurement. Table 10 shows a comparison of the analytical results and the measured results.

\section{Conclusion}

This paper describes an analysis of the natural frequencies of machine parts and a method to estimate the measure of uncertainty in manufactured machine parts. As a result of comparing the analytical results and the measured results, general machining errors were found to occur during the machining of the parts. These machining error mostly do not influence the natural frequencies. The results of this study show that careful machining and a decrease in the uncertainty of measurements of measurements are necessary.

\section{Acknowledgement}

The authors of this paper were supported by the Vibration Induced Durability Evaluation Center in Changwon National University.

\section{Reference}

1. Dong-ju Kim, CATIA BASIC Mechanical Design Master $<1>$, Science Technology, 2007.

2. Heui-huang Lee, Finite Element Simulations with ANSYS Wrkbench 12, Schroff Developmet Corp., 2010.

3. ISO/IEC Guide 98 : 1993, Guid to the Expression of Uncertainty in Measurement, ISO, 1993.

4. Kang-Hee Lee, Heung-Seok Kang, Kyung-Ho Yoon, and Hyung-Kyu Kim, "Measurement Uncertainty Estimation in Natural Frequency of the Nuclear Fuel Assembly", Proceedings of the Korean Society for Nosie and Vibration
Engineering Conference, 2010, pp. 540-541, 2010.10 .

5. Jung-Hoon Lee, Sang-Hwan Yoon, Dinh Minh Chau, and Min-Won Park, "Estimation of Measurement Uncertainty for Vibration Tests in the Machine Tool Main Spindle", Journal of the Korean Society for Precision Engineering, Vol. 28, No. 4, pp. 404-409, 2011.

6. KS R 1034 : 2006, Vibration testing methods for automobile parts, Korean Standards Service Network, 2006.

7. Yong-Bong Lee, Sang-Jun Suh, and Doo-Hee Lee, "Method of Uncertainty Estimation in the Calibration of Accelerometers", Proceedings of the Precision Engineering and Manufacturing, pp. 74-78, 1999.

8. C.S. Kang, J.W. Kim, J,A, Kim, and J.O. Choi, "Study on the Uncertainty arising from the Resolution Limit in Measurement", Proceedings of the Precision Engineering and Manufacturing, pp. 83-84, 2006. 